\title{
The Use of Digital Tools in Scholarly Activities. Empirical Findings on the State of Digitization of Science in Germany, Focusing on Saxony
}

\author{
Steffen Albrecht, Claudia Minet, Sabrina Herbst, Daniela Pscheida, \\ and Thomas Köhler
}

\begin{abstract}
Scholars are only beginning to understand what digitization means for their work, that is, the conduct of science. Taking a broad perspective on e-science, this paper provides empirical insights about two important aspects of the digitization of science, namely the use of digital tools in scholarly activities and scholars' perceptions of the change such use entails. The results of a German-wide survey of scholars and supplementary qualitative interviews in the years 2012 and 2013 show that the majority of scholars have adopted digital tools and that scholarly practice is affected profoundly by the use of such tools. This does not apply to web 2.0 tools, which remain a niche medium for some scholars. Small but significant differences exist between disciplines, and decisions about individual tool use are utilitarian. Further research is needed to assess the changes from a longitudinal perspective.
\end{abstract}

Keywords E-science $\cdot$ Digitization $\cdot$ Scholarly practice $\cdot$ Survey results

\section{E-Science, Cyberscience, Science 2.0: The Digitization of Science Is on the Move}

Ever since Galileo's successful use of the telescope, scientists have relied on new tools in their scholarly practice (Hankins and Silverman 1995). The advent of computer

\author{
C. Minet \\ Hochschule Mittweida-University of Applied Sciences, Mittweida, Germany \\ e-mail: Minet@hs-mittweida.de \\ S. Herbst · D. Pscheida · T. Köhler \\ Media Center, Technische Universität Dresden, Dresden, Germany \\ e-mail: Sabrina.herbst@mailbox.tu-dresden.de \\ T. Köhler \\ e-mail: Thomas.koehler@tu-dresden.de \\ S. Albrecht ( $\varangle)$ \\ Berlin, Germany \\ e-mail: Steffen.albrecht@berlin.de


technology and digital networks was no exception, impacting not only the communication of research, but also the production of new knowledge. The World Wide Web with its network of hypertexts and its gradual change to web 2.0 with the additional manifestation of online social networks reinforce this impact and generate more potential. Although this cooperative process is not new (Bijker and Law 1992; Mayntz 1993), we are still only beginning to understand the changes that digitization entails for science. This paper furthers our understanding by providing empirical insights from an online survey of German scholars related to two specific aspects of the digitization of science, namely the use of digital tools in research, teaching and other scholarly activities, and scholars' perceptions of the change that such use brings.

Several terms have been proposed to apprehend how science is influenced by networked computer technologies. In 1999, the term e-science was introduced by John Taylor, General Director of the Research Council at the Office of Science and Technology of the UK. Taylor realized that new technological infrastructures were needed to foster global cooperation and data-intensive research in science. In other words, "e-science is not a new scientific discipline; rather, the e-science infrastructure developed [...] should allow scientists to do faster, better or different research" (Hey and Trefethen 2005: 818). Jim Gray specified what such "different research" could look like. He identified a "fourth paradigm" of scientific inquiry, "data-intensive science" that is characterized by the use of massive amounts of data to generate new theoretical models (Gray 2009: xix).

Michael Nentwich (2003) took a more holistic view of "cyberscience," including how academic work is organized, how it functions, and what its products are. While emphasizing its novelty compared to "traditional science," he technically assesses the digitization of science. In a recent update with René König, Nentwich used the term "cyberscience 2.0" to acknowledge the emergence of web 2.0 and its relevance to scholarly communication (Nentwich and König 2012). "science 2.0" is another term that emphasizes the importance of web 2.0 in facilitating openness and collaboration, focusing on online communication tools such as weblogs or wikis that open up science communication to external audiences (Waldrop 2008). ${ }^{1}$

Despite their nuances, all these terms are more similar than different. A broad notion is best suited to address the diverse issues involved in the digitization of science. Here and in the e-Science Research Network Saxony (www.escience-sachse n.de), we use the term e-science to comprise science, social science, and humanities disciplines, not only in research and collaboration, but also in teaching and science communication. In terms of technology, e-science comprises digital tools used in scholarly work that go beyond the individual computer and represent digital media or online-based, networked software systems.

Taking a broad perspective on digitization means normatively assessing this process without bias. This involves considering not only the changes in technology, but also changes induced by the social environment. Soon before e-science got onto

\footnotetext{
${ }^{1}$ Other notions of the digitization of science, include "digital scholarship" (Weller 2011) and "digital science" (European Commission 2013).
} 
the agenda, several authors recognized fundamental changes in how science was generally understood. "In response to the challenges of policy issues of risk and the environment, a new type of science - 'post normal' - is emerging," wrote Silvio Funtowicz and Jerome Ravetz (1993: 739). In a similar vein, Michael Gibbons and colleagues (1994) observed the emergence of what they called "mode 2" science, which was transdisciplinary and involved stakeholders from outside the scientific community. Both diagnoses overlap in noting an increasing external influence on science from politics, the economy, and civil society. The interrelations between technological and social change are not the main focus here, but developments within science such as the role of web 2.0 in opening up the research process might be part of a broader social change, in which technology plays only a moderating role.

The aim of this paper is to provide empirical observations of changes in scientific practice in relation to technological change, focusing on media use in science. Our approach is based on two fundamental assumptions. First, we find that considerable attention is devoted to the potential and affordances of digital technologies, but much less notice is taken of what scholars actually do with these technologies in their dayto-day practices, including potential non-adoption and refusal to use them (cf. Barassi and Trer 2012: 1282). Second, while there are a number of empirical case studies of scholars' use of technology in specific fields, we think a broad view on all aspects of scholarly practice is necessary to identify the changes, before the nature of such change in specific areas can be analyzed.

\section{The Empirical Question: Is Digitization Really on the Move?}

The empirical perspective of this paper goes beyond the rhetoric and euphoric expectations of some e-science discourse. We ask three questions. To what extent do scholars use digital media and online tools in their day-to-day academic activities? What kind of new practices emerge from such use? How do such changes in the conduct of science contribute to the bigger structural changes?

Technological innovation always takes place in form of co-evolution of engineering and social domains (Köhler 1998). Adoption theorists have pointed out that the adoption process is not just a matter of time, but also of individual differences, system characteristics, social influence, and facilitating conditions (Venkatesh and Bala 2008). Against this background, we can assume that the adoption of digital tools is not as straightforward a process as is depicted by some of the theoretical accounts discussed above: it is ongoing and has to be observed empirically to determine its state and direction. Our paper adds to the small, but growing empirical literature about the impact of using digital tools in science.

Previous research has shown that investigating scholars' use of digital tools poses methodological problems. There are a number of different approaches, all with specific merits and pitfalls. We can broadly distinguish a qualitative orientation with 
a focus on in-depth analysis of a limited number of cases, often based on stakeholder interviews or case studies (see, e.g., Currier 2011; RIN/NESTA 2010; Bullinger et al. 2010), and a quantitative orientation with a focus on assessing the whole field, often based on standardized surveys. As our aim is to provide a holistic and realistic assessment of the state of adoption, we mainly review previous quantitative research.

Lattemann et al. (2010), ZBW (2011), Donk (2012), and Pscheida and Köhler (2013) all address a limited target group (principal investigators in funded research projects, economics researchers and students, researchers at one specific university, and scholars at universities in Saxony, respectively). Thus, none of this research is particularly helpful in terms of either methodology or results. In an early study of 1477 UK re-searchers, Procter et al. (2010) found that 60\% used a web 2.0 tool (blogging, commenting, sharing resources, or contributing to wikis) in their scholarly activities, but only $13 \%$ did so frequently. The authors consider this figure "rather low" and observe that frequent users are most likely to be computer scientists or mathematicians, engineers, or scholars in the arts and humanities. Ponte and Simon (2011) also focus on web 2.0 use, but based on a self-selected sample of 345 persons from across Europe. They report the use of wikis and blogs by about $40 \%$ of respondents, academic social networking sites by $35 \%$, and microblogging by $18 \%$ of researchers. Results for specific groups are not presented.

Bader et al. (2012) analyzed 1053 responses to an online survey of scholars at German universities. They found that communication tools such as e-mail (94\%), mailing lists (24\%), and Skype (21\%) were widely adopted, web 2.0 tools like blogs or research portals were much less used (6\% use wikis, $5 \%$ use research portals or social networking sites, $4 \%$ use academic blogs, and $2 \%$ use Twitter). The tools used varied greatly by discipline: wikis were mostly used in science and engineering, whereas mailing lists and blogs were more popular in humanities and social sciences, especially in law, and research portals were favored by social scientists. In general, the authors consider German researchers to be at an "early stage" of adopting digital communication tools.

Despite the small number of studies of sufficient scope and methodological quality, these results raise doubts about the predicted impacts of digital tools on science. In the best case, adoption is too early to have had a significant impact. In the worst case, apart from some small groups, scholars are not tempted to actually use digital tools in their work. The existing research shows that digital tool adoption in scholarly activities is low (apart from very popular tools such as search engines), that web 2.0 tools are much less likely to be used than more conventional ones, and that disciplines seem to play a role in the choice of tool.

\section{Hypotheses, Data, and Methods}

To remedy the obvious lack of comprehensive, quantitative research, our paper seeks to empirically assess the state of adoption of digital tools by scholars and their impacts on the basis of new data from the Science 2.0 Survey 2013 (Pscheida et al. 2014). 
Based on our above analysis of previous research, we assume that to have an impact on scientific activity, digital tools have to be used for scholarly purposes in the first place. This leads us to the following hypotheses and research questions.

Hypotheses. Our first two hypotheses concern the extent to which scholars use digital tools in their activities.

H1: The adoption of digital tools in scholarly activities is still in an early phase, with diffusion levels (Rogers 1995) below 50\% of the population ("early majority").

$\mathrm{H} 2$ : Web 2.0 tools like weblogs, wikis or microblogging are used by a minority of scholars for professional activities, with diffusion levels below $16 \%$ ("early adoption").

Our third hypothesis concerns the differences between disciplines and is formulated as research question, since previous research is inconclusive.

RQ1: Do scholars in different disciplines use digital tools differently?

Finally, we are interested in how digital tool use impacts on the conduct of science, leading to another research question.

RQ2: What changes in the conduct of science as a result of digital tool use do scholars perceive?

Data. We collected data in two related steps. First, an online survey of 778 scholars at German universities was conducted in autumn 2013, addressing questions such as scholars' use of 17 different tools and services, their academic and sociodemographic background, their motives for and attitudes to using digital tools (see Pscheida et al. 2014). ${ }^{2}$ Although quota sampling of universities was applied in the recruitment procedure, the sample shows some deviations from the population with regard to gender (women are slightly overrepresented), professional status (professors are overrepresented, research assistants or "WHK" underrepresented), discipline (with medicine strongly underrepresented, humanities, mathematics, and natural sciences slightly overrepresented), location, and type of university. While the latter two could be adjusted by weighting, the other deviations should be kept in mind in interpreting the results. In addition, all scholars at universities in the German federal state of Saxony were invited to participate in the same survey, with 442 questionnaires being submitted. The Saxony sample shows similar patterns of deviations from the population, except that with regard to disciplines, engineers and mathematicians/natural scientists are strongly overrepresented, whereas medicine and the fine arts are underrepresented.

The quantitative survey was supplemented in the first half of 2013 by 19 interviews with scholars in Saxony, chosen to map the various disciplines and status groups. The semi-structured interviews focused on the scholars' perception of the use of digital tools and of the changes this entails. Due to the variety of scholarly practices and lack of knowledge about the precise impact of digital tools on them, qualitative interviews were chosen to address our second research question.

Methods. The hypotheses and research questions were statistically analyzed, comparing the Saxony and German-wide samples. Adoption was measured by asking scholars "to what extent do you use the following?" followed by a list of 17 different

${ }^{2}$ The data set of the Science 2.0 Survey 2013 is open access: see www.escience-sachsen.de. 
online tools. Answers were categorized by frequency of use. In the analysis, only uses for scholarly work (research, teaching, research administration, and science communication) were taken into account. Based on Schmidt's (2007) definition, social networking sites, wikis, video/photo community portals, weblogs, microblogs, and social bookmarking services are regarded as "social software" or "web 2.0 tools," as they constitute social or hypertextual relationships of (at least partially) public character (Schmidt 2007: 32). The disciplines were categorized based on the definition of the German Federal Bureau of Statistics (2012) into arts and humanities; (natural) sciences (including mathematics); engineering and social sciences (including law and economics). Finally, the qualitative interviews were transcribed and anonymized, and qualitative content analysis methods were applied to the responses.

\section{Results}

\subsection{General Level of Adoption of Digital Tools in Scholarly Activities}

Scholarly activity at German universities in 2013 was affected considerably by the use of digital tools. Of all 17 tools the survey asked about, ten were used by more than $50 \%$ of all respondents in a professional context (with two others by $49 \%$, see Fig. 1). Only general-purpose social networking sites, online editors like Etherpads

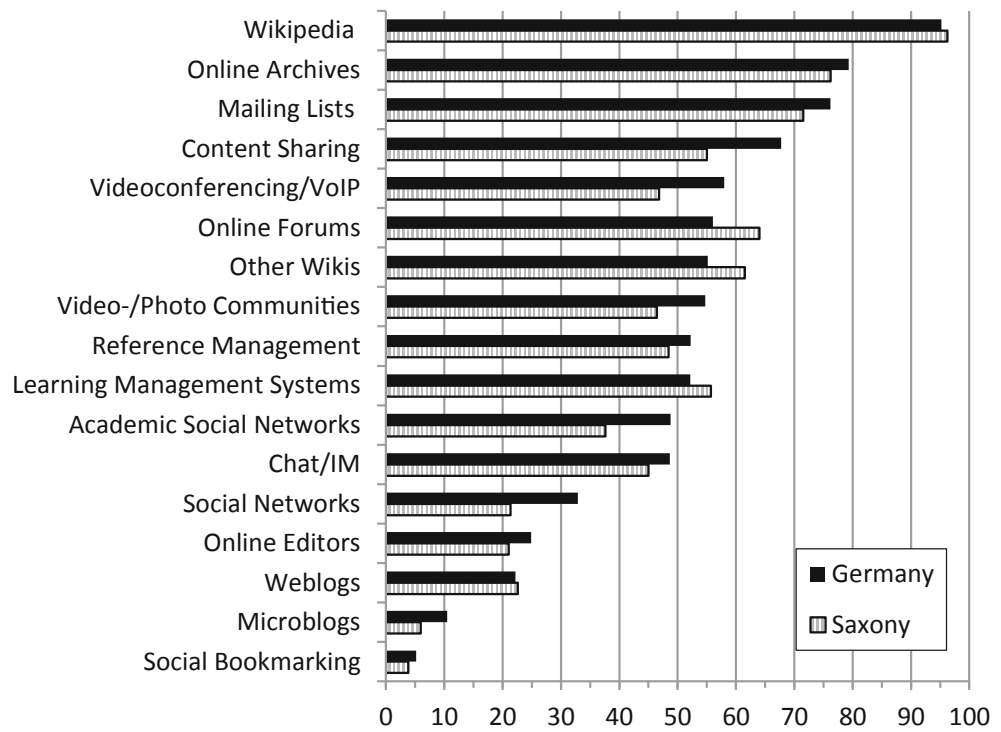

Fig. 1 Level of adoption (in \%) of digital tools in scholarly use in Germany and Saxony 
or Google Docs, weblogs, microblogs like Twitter, and social bookmarking services are used by less than about half of all respondents. Wikipedia is the tool with the broadest diffusion in academia, with $95 \%$ of respondents reporting to have used Wikipedia in their scholarly work. Comparably extensive more than three quarters of the respondents use online archives like Arxiv.org and mailing lists.

The pattern for scholars in Saxony is quite similar to the national one. Wikipedia, online archives, and mailing lists are the tools with the highest level of adoption in the context of scholarly work. Social networking sites, online editors, weblogs, microblogs, and social bookmarking services are used by less than half of the respondents, including professional social networking sites like Xing or Academia.edu. The general level of adoption of digital tools in Saxony is a bit lower than in Germany as a whole. The reverse is true for online forums (64\% in Saxony, 56\% in Germany) and wikis other than Wikipedia (62\% in Saxony, 55\% in Germany). Of course, such seems still to be a contradictory observation as many scientists recommend their students not to use digital tools like Wikipedia due to the "non-scientific" nature. So is especially valuable exploring in more detail practices of adoption among scientists.

In some cases, digital tools may be used more for general than work-related purposes (see Table 1). Content sharing and cloud services, video conferencing and VoIP ("online telephone") services, online forums, video/photo communities,

Table 1 General and work-related use (in \%) of digital tools in Germany and Saxony. Note the high level of general use

\begin{tabular}{l|l|l|l|l}
\hline \multirow{2}{*}{ Digital tool } & \multicolumn{2}{l}{ Germany } & Saxony & \\
\cline { 2 - 5 } & General & Work & General & Work \\
\hline Social networking sites & 57.9 & 32.9 & 51.1 & 21.0 \\
\hline Academic networking sites & 52.7 & 48.8 & 41.0 & 37.6 \\
\hline VoIP & 71.7 & 58.0 & 64.3 & 46.2 \\
\hline Microblogs & 15.1 & 10.5 & 5.9 & 1.6 \\
\hline Weblogs & 29.2 & 22.2 & 28.3 & 22.6 \\
\hline Wikipedia & 98.9 & 95.2 & 100 & 96.2 \\
\hline Other wikis & 56.5 & 55.1 & 63.6 & 61.5 \\
\hline Content sharing/cloud server & 73.5 & 67.7 & 64.3 & 54.5 \\
\hline Online editors & 26.7 & 24.9 & 24.4 & 21.0 \\
\hline Online forums & 65.3 & 56.0 & 74.0 & 64.0 \\
\hline Mailing lists & 77.4 & 76.2 & 74.0 & 71.5 \\
\hline Chat/IM & 69.1 & 48.7 & 69.2 & 44.3 \\
\hline Online archives & 79.8 & 79.3 & 76.7 & 76.2 \\
\hline Reference management & 52.2 & 52.2 & 49.1 & 48.4 \\
\hline Social bookmarking services & 5.9 & 5.2 & 4.3 & 3.8 \\
\hline Video/photo communities & 80.4 & 54.8 & 78.3 & 45.7 \\
\hline Learning management systems & 52.3 & 52.2 & 56.1 & 55.7 \\
\hline
\end{tabular}


chat/instant messaging (IM), social networking sites, and microblogs all show a significantly higher level of personal than professional use. Where data for comparison exists, the use of digital tools is more widespread among scholars than in the German population in general (cf. data from the ARD/ZDF Online Study 2013, van Eimeren and Frees 2013).

With regard to our first hypothesis, we can thus infer that the adoption of digital tools in scholarly activities has left the phase of early adoption and has reached a more mature state with more widespread use. Although a considerable number of scholars do not use certain digital tools, and some tools have not reached broad adoption, the majority of tools our survey asked about are used by more than $50 \%$ of respondents.

\subsection{Use of Web 2.0 Tools Among Scholars}

The situation is different for web 2.0 tools such as wikis, blogs, social networking sites, social bookmarking services, and video/photo communities. While about half of respondents use wikis, video/photo communities and academic social networking sites in work-related contexts, only between 5 and $32 \%$ of scholars use generalpurpose social networking sites, weblogs, and microblogs as well as social bookmarking services for work. Considering the broad adoption of digital tools in general and the length of time that web 2.0 tools have been in use, the latter have to be considered a niche product with regard to scholarly use. The figures for Saxony are comparable, but generally lower than for the national level (except for wikis, see above).

However, with regard to our second hypothesis, web 2.0 tools have a higher adoption level than the $16 \%$ "early adoption" rate, at both the national and the Saxony level, with the exception of microblogs and social bookmarking services. At the same time, only a minority of scholars use web 2.0 tools that have not been designed specifically for academics. Given that these tools have been in use for a long time and are well known among scholars (except for social bookmarking services, which about $50 \%$ of respondents said they didn't know about), we have to conclude that web 2.0 tools have only reached specific groups of scholars (cf. Pscheida et al. 2014: 18). It seems to be difficult for most scholars to find useful applications for these tools.

From the results of the survey, we can more generally infer that tools are adopted when a specific use is found for them. Most of the tools with high levels of adoption are specialized for one or more areas of scholarly work. Most respondents said that the digital tools they use are practical or make their work easier and faster (Pscheida et al. 2014: 24f.), indicating the prevalence of utilitarian motivation. This was not equally the case for all tools. General-purpose social networking sites and microblogs show a different pattern of use: both tools are used twice as often in a personal than a professional capacity, that is, utilitarian motivation was less important. The two main reasons for not using general-purpose social networking sites in a scholarly context are disagreement with the terms of use (indicated by $24 \%$ of those researchers who 
do not use them for work) and personal use (indicated by 18\%). For microblogs, the most salient obstacle is the lack of additional benefit (indicated by $56 \%$ of those researchers who don't use microblogs for work).

Besides the prevalence of pragmatic reasons, researchers who use web 2.0 tools (like academic network sites, weblogs, or microblogs) also mentioned an interest in new technologies or that these tools help to boost their reputation. This shows awareness of the social and hedonistic (as one could say) affordances of web 2.0 tools.

\subsection{Disciplinary Differences}

Our third hypothesis was about the differences between disciplines in scholars' adoption of digital tools. The results of the survey indicate a more nuanced picture than previous studies have drawn. Cross-tabulation and computation of Cramer's V (a bivariate measure of association) for the German study show small but significant differences in professional use of Wikipedia, wikis, online editors, mailing lists, online archives, reference management systems, social bookmarking services, and video/photo communities (see Table 2). In all other cases, no difference between disciplines in the use of digital tools for scholarly purposes is found.

Digital tools are most highly adopted in the (natural) sciences and in arts and humanities, whereas engineering and social sciences show lesser degrees of adoption. However, engineering scientists use wikis and video/photo communities quite heavily, and social scientists use mailing lists and online archives to a similar degree as the (natural) scientists.

For Saxony, significant differences between the disciplines are more frequent and related to other tools than in the German-wide study. Social networking sites, academic networking sites, VoIP, microblogs, weblogs, content sharing services, chat/instant messaging services, reference management systems, and learning management systems all show small but significant differences between disciplines (see Table 3). Social scientists use tools most across all categories, followed by scholars in arts and humanities. The only tools which are used more extensively by natural scientists and engineers are Wikipedia and other wikis, but these findings are not statistically significant.

The differences between the Saxony and German-wide results are striking. They might be explained by the special disciplinary structure of universities in Saxony, which have a strong emphasis on natural sciences and engineering. For Germany as a whole, such differences might exist, but are leveled off due to the mix of academic cultures and institutional structures across the various federal states. However, the differences are generally small, with low values of Cramer's V, so we can conclude with regard to our first research question that there are only small differences between the disciplines, highly dependent on the disciplinary context in which each tool is used. 
Table 2 Professional use (in \%) of online tools by scholars at German universities in 2013 across the most relevant disciplines: arts and humanities; (natural) sciences; engineering and social sciences

\begin{tabular}{|c|c|c|c|c|c|c|}
\hline Digital tool & $\begin{array}{l}\text { General } \\
n=778\end{array}$ & $\begin{array}{l}\text { Humanities } \\
n=225\end{array}$ & $\begin{array}{l}\text { Natural } \\
\text { sciences } \\
n=243\end{array}$ & $\begin{array}{l}\text { Engineering } \\
n=116\end{array}$ & $\begin{array}{l}\text { Social } \\
\text { sciences } \\
n=133^{\mathrm{a}}\end{array}$ & $\begin{array}{l}\text { Cramer's } \\
V^{\mathrm{b}}\end{array}$ \\
\hline $\begin{array}{l}\text { Social } \\
\text { networking } \\
\text { sites }\end{array}$ & 32.9 & 37.6 & 32.2 & 24.1 & 35.1 & - \\
\hline $\begin{array}{l}\text { Academic } \\
\text { networking } \\
\text { sites }\end{array}$ & 48.8 & 48.7 & 53.5 & 44.0 & 53.8 & - \\
\hline VoIP & 58.0 & 57.8 & 60.7 & 57.8 & 56.4 & - \\
\hline Microblogs & 10.5 & 12.0 & 10.7 & 8.6 & 11.9 & - \\
\hline Weblogs & 22.2 & 25.8 & 23.0 & 16.2 & 23.3 & - \\
\hline Wikipedia & 95.1 & 93.8 & 98.8 & 94.9 & 90.2 & .112 \\
\hline Other wikis & 55.1 & 52.2 & 68.7 & 56.0 & 44.4 & .114 \\
\hline $\begin{array}{l}\text { Content } \\
\text { sharing/cloud } \\
\text { server }\end{array}$ & 67.7 & 69.9 & 70.8 & 59.5 & 69.9 & - \\
\hline Online editors & 24.8 & 28.0 & 26.7 & 22.2 & 21.2 & .092 \\
\hline Online forums & 56.0 & 58.0 & 59.3 & 65.5 & 45.1 & - \\
\hline Mailing lists & 76.2 & 81.0 & 76.9 & 63.8 & 75.2 & .093 \\
\hline Chat/IM & 48.7 & 51.8 & 54.5 & 40.5 & 49.6 & - \\
\hline Online archives & 79.3 & 86.3 & 78.2 & 67.5 & 78.9 & .110 \\
\hline $\begin{array}{l}\text { Reference } \\
\text { management }\end{array}$ & 52.2 & 53.3 & 63.6 & 33.3 & 43.6 & .158 \\
\hline $\begin{array}{l}\text { Social } \\
\text { bookmarking } \\
\text { services }\end{array}$ & 5.3 & 4.4 & 9.1 & 2.6 & 3.8 & .100 \\
\hline $\begin{array}{l}\text { Video/photo } \\
\text { communities }\end{array}$ & 54.8 & 64.2 & 48.6 & 57.8 & 43.3 & .116 \\
\hline $\begin{array}{l}\text { Learning } \\
\text { management } \\
\text { systems }\end{array}$ & 52.2 & 56.9 & 44.7 & 51.3 & 59.0 & - \\
\hline
\end{tabular}

aincluding law and economics

${ }^{b}$ significance $\alpha<.05$

- indicates that no significant correlation is observed

If discipline does not explain differences in the use of digital tools, how else might we explain them? Some indications can be found in the 19 semi-structured interviews that were conducted to supplement the quantitative investigation. Content analysis methods according to Mayring (2000) were used to analyze these. In a first step, categories of analysis were generated based on the interview guideline. These categories were then tested against the empirical material, and continuously 
Table 3 Professional use (in \%) of online tools by scholars at universities in Saxony in 2013 across the most relevant disciplines: arts and humanities; (natural) sciences; engineering and social sciences

\begin{tabular}{l|l|l|l|l|l|l}
\hline Digital tool & $\begin{array}{l}\text { General } \\
n=442\end{array}$ & $\begin{array}{l}\text { Humanities } \\
n=49\end{array}$ & $\begin{array}{l}\text { Natural } \\
\text { sciences } \\
n=124\end{array}$ & $\begin{array}{l}\text { Engineering } \\
n=191\end{array}$ & $\begin{array}{l}\text { Social } \\
\text { sciences } \\
n=47^{\mathrm{a}}\end{array}$ & $\begin{array}{l}\text { Cramer's } \\
\mathrm{V}^{\mathrm{b}}\end{array}$ \\
\hline $\begin{array}{l}\text { Social } \\
\text { networking } \\
\text { sites }\end{array}$ & 21.3 & 28.6 & 21.8 & 13.6 & 34.0 & .165 \\
\hline $\begin{array}{l}\text { Academic } \\
\text { networking } \\
\text { sites }\end{array}$ & 37.6 & 32.7 & 37.9 & 31.9 & 66.0 & .165 \\
\hline VoIP & 46.8 & 42.9 & 53.2 & 39.3 & 63.8 & .145 \\
\hline Microblogs & 5.9 & 6.1 & 4.8 & 1.6 & 21.3 & .197 \\
\hline Weblogs & 24.0 & 30.6 & 25.0 & 16.2 & 38.3 & .133 \\
\hline Wikipedia & 96.2 & 91.8 & 98.4 & 96.3 & 93.6 & - \\
\hline Other wikis & 61.5 & 59.2 & 64.5 & 61.8 & 61.7 & - \\
\hline $\begin{array}{l}\text { Content } \\
\text { sharing/cloud } \\
\text { server }\end{array}$ & 55.0 & 71.4 & 50.8 & 47.1 & 72.3 & .146 \\
\hline Online editors & 27.8 & 20.4 & 25.8 & 15.7 & 31.9 & - \\
\hline Online forums & 64.0 & 49.0 & 67.7 & 64.9 & 68.1 & - \\
\hline Mailing lists & 71.5 & 77.6 & 75.8 & 64.4 & 85.1 & - \\
\hline \begin{tabular}{l} 
Chat/IM \\
\hline Online archives
\end{tabular} & 75.0 & 42.9 & 54.8 & 36.1 & 55.3 & .140 \\
\hline $\begin{array}{l}\text { Reference } \\
\text { management }\end{array}$ & 48.4 & 51.0 & 51.6 & 40.8 & 66.0 & .138 \\
\hline $\begin{array}{l}\text { Social } \\
\text { bookmarking } \\
\text { services }\end{array}$ & 3.8 & 4.1 & 5.6 & 3.7 & 2.1 & - \\
\hline $\begin{array}{l}\text { Video/photo } \\
\text { communities }\end{array}$ & 46.4 & 53.1 & 45.2 & 41.9 & 59.6 & - \\
\hline $\begin{array}{l}\text { Learning } \\
\text { management } \\
\text { systems }\end{array}$ & 55.7 & 77.6 & 53.2 & 49.2 & 80.9 & .175 \\
\hline incuding & 71.4 & 77.4 & 74.9 & 85.1 & - \\
\hline
\end{tabular}

aincluding law and economics

$\mathrm{b}_{\text {significance } \alpha<.05}$

- indicates that no significant correlation is observed

revised and amended with sub-categories during analysis. In a third step, relations and causalities between categories and sub-categories of analysis were carved out. 
The results do not point to disciplinary differences, but instead to the influence of the tangible working practices in which scholars are involved. These can be collaborations, such as in projects with many partners (interview 8), working groups (interviews 1,7 ) or institutions (interview 7), but also institutional contexts, such as when "interdepartmental" wikis are created (interview 8) or the institutional website is used for information sharing, because "those who are concerned and who will look at the information [are] mainly limited to the institute" (interview 19).

Another important determinant for the use of a digital tool is its quality and suitability for specific working contexts. Digital tools are expected to make working processes more efficient: "the biggest obstacle and a huge inefficiency is how we communicate data. We copy, we process data again and again" (interview 3 ). Wikis, for example, are used to facilitate collaborative work: "to manage data, I do not have to send e-mails around where nobody knows what the current state is" (interview 8). Similar motivations underlie the use of cloud services like Dropbox (interview 5) or instant messaging clients and VoIP services such as Skype and ICQ (interview 8). The use of e-mail for collaborative work is considered rather inefficient (interviews $3,5,8)$.

Wikis can be used as "encyclopedias," to provide information in a structured and clearly arranged way, "where you can collect things that you maybe will have to look up in future" (interview 19). Wikis are repositories "where all kinds of information are collected" (interview 19); "just to preserve collected knowledge that you can look up again" (interview 7); "where knowledge for all is provided" (interview 1); "to upload files in the current state, where it can then be downloaded" (interview 8). This also refers to the exchange of administrative information, such as in managing technical infrastructure (interview 9) or as an organizational manual (interviews 9, 15).

However, once data protection becomes an issue, web-based tools and services are not used despite their efficiency savings: "I would have proposed Dropbox, but because of data protection requirements we cannot use it" (interview 11). Instead, local network servers are used to exchange data, especially in cases where the cooperation is limited to partners in the same institution: "to some extent we have this in our working group internally, using the university file system. There we have our account and there is our stuff, i.e. the programs, and everybody in our working groups who wants can use it" (interview 1). Yet, web-based applications are important "especially if you collaborate with external partners" (interview 8). From a qualitative perspective, too, the conclusion is that the requirements of collaborative work and the affordances of the technology have a stronger influence on scholars' choice of digital tools than professional affiliations.

\subsection{Changing Scholarly Practices}

The above analysis sheds some light on an important prerequisite for any changes in the conduct of science induced by digitization, namely the actual use of digital 
tools in scholarly activity. But this is just a necessary, not a sufficient, condition for change. The semi-structured interviews indicate what kind of changes scholars in Saxony perceive. Of course, such perceptions might not give an accurate account of the situation, but until better data is available (e.g., from long-term observations of scholarly practices), qualitative interpretation of perceptions from actors within the field with a variety of perspectives gives a good approximation.

Our interview partners indicated a number of changes in their work practices which they did not see as related to technology use, but rather to a changing social environment in science. The importance of collaborative work is seen as growing. Short-term research projects can require the use of certain digital tools (interview 8) or new competencies, such as writing research proposals (interview 7). Work biographies are seen as becoming more flexible. Temporary retirement affects the way of working and the adoption of new technologies: "so I did not slowly get used to [web-based tools], I knew work without them and when I was re-entering, I had to use and become acquainted with the different tools" (interview 1). This flexibility also includes geographical mobility and increasing independence from local contexts: the use of Skype "has actually naturalized through stays abroad, only to stay in touch" (interview 14).

Interviewees mentioned several changes in their personal way of working that they related to technological conditions. The entire process of scientific enquiry, including literature research, has tremendously accelerated: "you simply find something immediately rather than writing letters to ask: "what did you do there actually?"' (interview 19). Before using digital archives, "we had to [...] ask for interlibrary loan literature and had to wait" (interview 16). Technology is explicitly mentioned as an attractive agent of change: "so I still remember card indexes in libraries and of course when the online catalog was there, then you liked to use it" (interview 14). This also relates to the management of literature: "I think the trigger was that the university offered Refworks and that we got an account for the group" (interview 1).

Communication processes seem to be particularly affected: "if I have a meeting with someone today, I just search for her or him on the Internet before and look up who it is. If I'm lucky, I have a small CV or at least I see what she or he does" (interview 13). Communication is increasingly shifting into virtual spaces (interview 17): "in times of my diploma one rather met personally, [...] so if calling on the telephone did not work, then one rather met personally somehow" (interview 7). What is more, the way information is stored and made available has changed: "I have scarcely printed or written documents, [...] all of my documents are digitized. Either as a PDF or HTML page or in another format, like video or other scripts or programs" (interview 2). This in turn influences the access to information: "in the past, I can still remember that I used a usual lexicon from the bookshelf, which I not so long ago just sold because I have not been using it anymore and it stood around useless" (interview 9). Again, the affordances of new technologies are described as attractive: "I notice that I still prefer printed paper, but this changes step by step and in ever more cases, I do not print the reports I read, but rather read them on the screen somewhere and if I have the opportunity also highlight sections as it is possible with various apps on the iPad, 
then for me this actually replaces printed and nicely annotated reports because I thus have the same opportunities to work" (interview 18).

Advancements in data infrastructure, including the availability of faster and more efficient Internet connections or better computing capacities, primarily affect information sharing and data analysis, "just because it was somehow difficult to load ten megabytes from the Internet with the first emerging DSL connections" (interview 15), and "if one then changed from modem to ISDN and DSL, then you increasingly used it, it went faster" (interview 14). The ubiquity of computing and network power eases the work process "because you don't have to rack your brain, should I resize photos in the dataset or not, instead you just send it" (interview 12). Parts of data analysis are replaced by automated processes: "30 years ago or maybe more, you went with stacks of punch cards to the computing center and tried to compute a t-test or something similar, and now you just have to push the button" (interview 5, cf. interview 19). The availability of portable devices, "that we have just passed on to equip all staff with laptops, [i.e.] no location-bounded work on the computer we sit in front of anymore" (interview 15), supports highly flexible working practices.

Finally, the attitude of researchers toward new technologies, their openness and curiosity to try something new also affect their working practices: "then I had a telephone bill of about 80 marks which was very high for a student, just because I intensively explored the Internet" (interview 16). Or, as another interviewee said: "whenever a new technology emerges, I deal with it and watch to see if it makes sense to use it" (interview 3). Last but not least, cost-benefit considerations also play an important role: "If I have the feeling that there is something that helps me on [...] then I try it" (interview 19, cf. interview 16).

Coming back to our second research question about perceived changes in the conduct of science, the qualitative interviews confirm the result from the survey that in science, digital tools are widely adopted. Scholars are not only using digital tools for work, but also perceive their work as being changed by these tools, partly even dramatically. The change is described as making research more efficient and faster, and this acceleration also affects communication and collaboration.

The precise nature of this change requires more thorough analysis. From the results presented here, it is clear that technology is just one of the driving forces underlying the change, and that the increasing collaboration and mobility of scholars is another important factor interacting with the use of technology. With regard to the motivations for decisions about technology use, both the qualitative and the quantitative analysis underscore the importance of a pragmatic, utilitarian orientation. The affordances of digital technologies and the institutional contexts appear less perceptible, but also relevant factors in determining which technologies are used and to what extent they affect scholarly work. Based on our study, more detailed research into the interplay of these factors can be designed and carried out. 


\section{Summary and Discussion}

Our study empirically observes the digitization of science and its effects on scholarly practices. Starting from the individual use of digital tools by scholars as the most important element in the digitization process, we have measured the adoption of digital tools in scholarly work in Germany, focusing on Saxony. By critically extending previous work, our results show that the majority of scholars adopted such tools and that scholarly practice is affected profoundly by their use. We have also shown that this does not apply to all kinds of tools. Web 2.0 and its affordances for scholars might stimulate much debate, but a minority of scholars only uses tools such as weblogs and social networking sites. Presumably, a neglect of epistemological and technological sociological analyses of scientists' activities can be identified, which has to be overcome. This goes hand in hand with the need for a review with regard to digital science technologies, which has so far been reflected neither in the curricula for training nor in the self-image of the scientists.

Our survey indicates that there are small but significant differences in disciplinary adoption of digital tools. The arts and humanities show higher levels of adoption than engineering and the social sciences. However, the degree of use greatly depends on the tool in question. Similarly, the change which the tools induce varies greatly by scholarly activity. Our analysis of the qualitative interviews has confirmed that tools are chosen based on utilitarian motives, and given rise to new hypothesis about the interrelation between individual, technological, and systemic factors of change in the digitization of science.

In comparison with the discourse on e-science, cyberscience, and science 2.0, but also to the results of previous empirical studies, our results show that the digitization of science is indeed on the move in Germany. The level of adoption is higher than in previous studies, with many digital tools reaching broad professional diffusion. The full potential of e-science has yet to be exploited. Our interviews indicate that institutional cultures and the affordances of the technologies do not fit well enough to let these online applications evolve into widely used professional scholarly tools. Still there is need for further consideration, including individual competency development.

Our results certainly do not provide definite answers to the questions raised at the beginning of this paper. As well, one may observe different and perhaps contradictory patterns of adopting digital tools in science. The scope of our analysis is too limited to assess the digitization of science broadly. Thus, we deliberately chose to analyze tool use first, to gain as precise a measure of adoption as possible. More detailed analysis of the specific kind of tool use would merit attention, taking into account the institutional conditions of science or the affordances of digital tools. Moreover, the digitization of science is an ongoing process, which calls for a longitudinal perspective toward understanding the character of digitization. As stated in the introduction, there are still very few empirical studies on the digitization of science. Our aim was to contribute to a growing body of (empirical) research and we hope to have laid the foundations for future, longitudinal studies. 


\section{References}

Bader, A., Fritz, G., Gloning, T.: Digitale Wissenschaftskommunikation 2010-2011. Eine OnlineBefragung. Gießener Elektronische Bibliothek, Gießen. https://www.yumpu.com/de/document/ $\mathrm{read} / 6774710 /$ digitale-wissenschaftskommunikation-2010-2011-eine-online (2012). Accessed 11 March 2020

Barassi, V., Trer, E.: Does Web 3.0 Come After Web 2.0? Deconstructing theoretical assumptions through practice. New Media \& Soc. 14(8), 1269-1285 (2012)

Bijker, W.E., Law, J. (eds.): Shaping Technology / Building Society: Studies in Sociotechnical Change. MIT Press, Cambridge (1992)

Bullinger, A.C., Hallerstede, S.H., Renken, U., Söldner, J.-H., Möslein, K.M.: Towards Research Collaboration-a Taxonomy of Social Research Network Sites. AMCIS 2010. Lima, Peru (2010)

Currier, S.: Open Science Project: Final Report. Centre for Research Communications. University of Nottingham, Nottingham (2011)

Donk, A.: Ambivalenzen der Digitalisierung. Neue Kommunikations- und Medien-technologien in der Wissenschaft. MV Wissenschaft, Münster (2012)

European Commission: Digital science in Horizon 2020. Concept Paper by DG Conect. http://ec. europa.eu/digital-agenda/en/digital-science (2013). Accessed 21 July 2013

Funtowicz, S.O., Ravetz, J.R.: Science for the Post-normal Age. Futures 25(7), 739-755 (1993)

German Federal Bureau of Statistics: Bildung und Kultur. Studierende an Hochschulen - Fächersystematik 2013. Fachserie 11, Reihe 4.1, WS 2012/2013. Federal Bureau of Statistics, Wiesbaden. https://www.destatis.de/DE/Methoden/Klassifikationen/BildungKultur/StudentenPruefu ngsstatistik.pdf?_blob=publicationFile (2012). Accessed 8 Mar 2020

Gibbons, M., Limoges, C., Nowotny, H., Schwartzman, S., Scott, P., Trow, M.: The New Production of Knowledge: The Dynamics of Science and Research in Contemporary Societies. Sage, London (1994)

Gray, J.: Jim Gray on eScience: A Transformed Scientific Method. Based on a presentation by Jim Gray at the NRC-CSTB Meeting in Mountain View, 11 January 2007, In: Hey, T., Tansley, S., Tolle, K. (eds.) The Fourth Paradigm. Data-Intensive Scientific Discovery, pp. xvii-xxxi. Microsoft Research, Redmond (2009). http://research.microsoft.com/en-us/collaboration/fourth paradigm/. Accessed 8 Mar 2011

Hankins, T.L., Silverman, R.L.: Instruments and the Imagination. Princeton University Press, Princeton, NJ (1995)

Hey, T., Trefethen, A.E.: Cyberinfrastructure and E-science. Science 308, 818-821 (2005)

Köhler, T.: Technikgenese als sozialer Prozeß: Das Beispiel Telefon und die Konsequenzen für neue Informations- und Kommunikationstechnologien. In: Coenen, O., Anke, P. (eds.) Der technologische Wandel am Ende des 20. Jahrhunderts, pp. 61-74. Shaker-Verlag, Aachen (1998)

Lattemann, C., Kallischnigg, M., Stieglitz, S.: Einsatz und Nutzung von Social Software in kooperativen Forschungsprojekten. In: Schumann, M.; Kolbe, L.M.; Breitner, M.H., Frerichs, A. (eds.): Multikonferenz Wirtschaftsinformatik 2010, pp. 1783-1793. Universitätsverlag Göttingen, Göttingen (2010). http://webdoc.sub.gwdg.de/univerlag/2010/mkwi/03_anwendungen/iktgestue tzte_unternehmenskommunikation/05_einsatz_und_nutzung_von_social_software_in_kooper ativen_forschungsprojekten.pdf. Accessed 11 Mar 2020

Mayntz, R.: Große technische Systeme und ihre gesellschaftstheoretische Bedeutung. Kölner Zeitschrift für Soziologie und Sozialpsychologie 45(1), 97-108 (1993)

Mayring, P.: Qualitative content analysis. Forum qualitative social research 1(2), Art. 20. http:// nbn-resolving.de/urn:nbn:de:0114-fqs0002204 (2000)

Nentwich, M.: Cyberscience. Research in the age of the Internet. Austrian Academy of Sciences Press, Wien (2003)

Nentwich, M., König, R.: Cyberscience 2.0. Research in the age of digital social networks. Campus, Frankfurt am Main and New York (2012)

Ponte, D., Simon, J.: Scholarly communication 2.0: exploring researchers' opinions on Web 2.0 for scientific knowledge creation, evaluation and dissemination. Serials Rev. 37(3), 149-156 (2011) 
Procter, R., Williams, R., Stewart, J., Poschen, M., Snee, H., Voss, A., Asgari-Targhi, M.: Adoption and use of Web 2.0 in scholarly communications. Philos. Trans. R. Soc. A 368, 4039-4056 (2010)

Pscheida, D., Köhler, T.: Wissenschaftsbezogene Nutzung von Web 2.0 und Online-Werkzeugen in Sachsen 2012. Studie des "eScience - Forschungsnetzwerks Sachsen". Medienzentrum der Technischen Universität Dresden, Dresden (2013)

Pscheida, D., Albrecht, S., Herbst, S., Minet, C., Köhler, T.: Nutzung von Social Media und onlinebasierten Anwendungen in der Wissenschaft. Erste Ergebnisse des Science 2.0-Survey 2013 des Leibniz-Forschungsverbunds „Science 2.0“. Medienzentrum der Technischen Universität Dresden, Dresden (2014)

Research Information Network and NESTA: Open to all? case studies of openness in research: a joint RIN / NESTA report. http://www.rin.ac.uk/system/files/attachments/NESTA-RIN_Open_S cience_V01_0.pdf (2010). Accessed 11 Mar 2020

Rogers, E.M.: Diffusion of Innovations. 5th ed. Free Press, New York (1995)

Schmidt, J.H.: Social Software: facilitating information-, identity- and relationship management. In: Burg, T.N., Schmidt, J. (eds.): BlogTalks reloaded, pp. 31-49. Books on Demand, Norderstedt (2007)

van Eimeren, B., Frees, B.: Ergebnisse der ARD/ZDF-Onlinestudie 2013. Media Perspektiven $7-$ 8/2013, pp. 358-406. http://www.ard-zdf-onlinestudie.de/files/2013/Eimeren_Frees.pdf (2013). Accessed 11 Mar 2020

Venkatesh, V., Bala, H.: Technology acceptance model 3 and a research agenda on interventions. Decis. Sci. 39(2), 273-315 (2008)

Waldrop, M. Mitchell: Science 2.0. Sci. Am. 298(5), 68-73 (2008)

Weller, M.: The digital scholar: how technology is transforming scholarly practice. Bloomsbury Academic. London, New York (2011). https://www.bloomsburycollections.com/book/the-dig ital-scholar-how-technology-is-transforming-scholarly-practice. Accessed 11 Mar 2020

ZBW: World Wide Wissenschaft - Wie professionell Forschende im Internet arbeiten. Kiel: ZBW Leibniz-Informationszentrum Wirtschaft (2011)

Open Access This chapter is licensed under the terms of the Creative Commons Attribution 4.0 International License (http://creativecommons.org/licenses/by/4.0/), which permits use, sharing, adaptation, distribution and reproduction in any medium or format, as long as you give appropriate credit to the original author(s) and the source, provide a link to the Creative Commons license and indicate if changes were made.

The images or other third party material in this chapter are included in the chapter's Creative Commons license, unless indicated otherwise in a credit line to the material. If material is not included in the chapter's Creative Commons license and your intended use is not permitted by statutory regulation or exceeds the permitted use, you will need to obtain permission directly from the copyright holder. 